\title{
Electrocardiographic Changes in COVID-19 Patients: A Hospital-based Descriptive Study
}

Deepalakshmi Kaliyaperumal $^{1} \odot$ Kumar Bhargavi $^{2} \odot$, Karthikeyan Ramaraju ${ }^{3} \odot$, Krishna S Nair ${ }^{4}$, Sudha Ramalingam ${ }^{5} \odot$, Murali $^{\circ}$ Alagesan ${ }^{6}(1)$

\begin{abstract}
Background: Coronavirus disease-2019 (COVID-19) infection is a multisystem disease not restricted to the lungs. It has a negative impact on the cardiovascular system by causing myocardial damage, vascular inflammation, plaque instability, and myocardial infarction. The presence of myocardial injury is a poor prognostic sign. Electrocardiogram (ECG), a simple bedside diagnostic test with high prognostic value, can be employed to assess early cardiovascular involvement in such patients. Various abnormalities in ECG like ST-T changes, arrhythmia, and conduction defects have been reported in COVID-19. We aimed to find out the ECG abnormalities of COVID-19 patients.

Methods: We performed a cross-sectional, hospital-based descriptive study among 315 COVID-19 in-patients who underwent ECG recording on admission. Patients' clinical profiles were noted from their records, and the ECG abnormalities were studied.

Results: Among the abnormal ECGs 255 (81\%), rhythm abnormalities were seen in 9 patients (2.9\%), rate abnormalities in 115 patients (36.5\%), and prolonged PR interval in 2.9\%. Short QRS complex was seen in $8.3 \%$. QT interval was prolonged in $8.3 \%$ of the patients. Significant changes in the ST and T segments (42.9\%) were observed. In logistic regression analysis, ischemic changes in ECG were associated with systemic hypertension and respiratory failure.

Conclusion: In our study, COVID-19 patients had ischemic changes, rate, rhythm abnormalities, and conduction defects in their ECG. With this ongoing pandemic of COVID-19 and limited health resources, ECG-a simple bedside noninvasive tool is highly beneficial and helps in the early diagnosis and management of cardiac injury.

Keywords: Coronavirus disease-2019, Electrocardiogram change, Rate abnormalities, ST-T changes.

Indian Journal of Critical Care Medicine (2022): 10.5005/jp-journals-10071-24045
\end{abstract}

\section{INTRODUCTION}

A cluster of pneumonia cases were reported due to "severe acute respiratory syndrome coronavirus 2" (SARS-CoV-2) at the end of 2019 in the city of Wuhan, in the Hubei Province of China. Soon coronavirus disease-2019 (COVID-19) was declared as a pandemic owing to its rapid spread across the countries. ${ }^{1}$ Initially regarded as a respiratory infection, COVID-19 is now known to affect all major systems in the body. Quite a lot is discussed in literature last year about COVID-19 and its effect on lungs and systemic response. However, very little is debated about cardiovascular involvement in COVID. It has been observed that lung involvement is more severe in patients with preexisting cardiac involvement. However, in sharp contrast new-onset cardiac involvement is also noted in a few patients and few patients do present with cardiac symptoms alone without lung involvement. ${ }^{2}$ The spectrum of presentation is wide-ranging from patients having no cardiac disease at all, asymptomatic but with elevated cardiac markers, having symptoms of overt cardiac disease such as angina, cardiogenic shock, heart failure, cardiac arrhythmias, and sudden cardiac death.

Arrhythmia and acute cardiac injury were reported in 16.7 and $7.2 \%$ of the COVID patients. ${ }^{3}$ In addition to the systemic inflammatory response, the physiological mechanisms identified to cause cardiac involvement in COVID-19 patients are hypoxemia-related myocardial cell injury and endothelial cell damage due to upregulated expression of angiotensin-converting enzyme 2 (ACE 2) in the heart and lungs. ${ }^{4}$

The electrocardiogram (ECG) changes reflect cardiac involvement with diverse manifestations. Arrhythmia and
${ }^{1}$ Department of Physiology, PSG IMSR, Coimbatore, Tamil Nadu, India

2,4,6 Department of Medicine, PSG IMSR, Coimbatore, Tamil Nadu, India ${ }^{3}$ Department of Respiratory Medicine, PSG IMSR, Coimbatore, Tamil Nadu, India

${ }^{5}$ Department of Community Medicine, PSG IMSR, Coimbatore, Tamil Nadu, India

Corresponding Author: Kumar Bhargavi, Department of Medicine, PSG IMSR, Coimbatore, Tamil Nadu, India, Phone: +91 9855478899, e-mail: kmcbhargavi@gmail.com

How to cite this article: Kaliyaperumal D, Bhargavi K, Ramaraju K, Nair KS, Ramalingam S, Alagesan M. Electrocardiographic Changes in COVID-19 Patients: A Hospital-based Descriptive Study. Indian J Crit Care Med 2022;26(1):43-48.

Source of support: Nil

Conflict of interest: None

conduction defects are found to be more prevalent among SARS-CoV-2-infected individuals. ${ }^{5}$ Myocardial ischemia, myocarditis, shock, hypoxia, and electrolyte abnormalities were the factors identified to cause arrhythmias. ${ }^{6}$ The presence of cardiac involvement may imply poor prognosis and an adverse outcome. ${ }^{7}$ Therefore, it is pertinent to assess and monitor the cardiac abnormalities paving way for a prompt action. ECG, a simple bedside diagnostic test with high prognostic value, can be employed to assess cardiovascular involvement in COVID-19 patients. We aimed to find out the ECG abnormalities of patients with SARS-CoV-2 infection. 


\section{Materials and Methods}

This cross-sectional, hospital-based descriptive study was conducted among 315 COVID-19 patients admitted in our tertiary care center during October to December 2020 after obtaining the human institutional ethics committee clearance and informed consent from the patients participating in the study [IHEC NO: Project No: 20/217]. Patients whose COVID status was confirmed by real-time reverse transcriptase polymerase chain reaction on nasopharyngeal and oropharyngeal swabs were included in the study.

Consecutive patients admitted to our hospital with SARSCoV-2-positive status underwent ECG testing on admission and were included in the study. Patients' clinical profiles that include symptoms, duration, and severity of illness, and comorbid status were noted from their clinical records. ECGs were reviewed and interpreted by two physicians (together responsible for the interpretation of $>100,000$ ECGs per year) who were blinded to the clinical status of the patients. Patients with ventricular pacing, immune suppression, stroke, malignancy and patients on beta blockers and anti-arrhythmic drugs were excluded.

The ECG data include heart rate, rhythm categorized as normal sinus rhythm or atrial fibrillation/flutter, atrial premature contractions, ventricular premature contractions, atrioventricular block, axis deviation, bundle branch block, intraventricular conduction block (QRS duration of $>110 \mathrm{~ms}$ ), Bazett-corrected QT interval (in milliseconds), presence of left or right ventricular hypertrophy, myocardial infarction, and the presence of ST segment or T-wave changes (localized ST elevation, localized T-wave inversion, or other nonspecific repolarization abnormalities).

\section{Statistical Analysis}

The data collected from the patients were tabulated using Microsoft Excel. Descriptive statistics were employed for analysis. Data were expressed as mean \pm standard deviation for continuous variables and proportions for categorical variables. Logistic regression analysis was employed to study the association between clinical variables and occurrence of various types of ECG abnormalities. The results were expressed in odds ratio with $95 \%$ confidence interval after adjusting for important confounders.

\section{Results}

A total of 315 patients satisfying the inclusion criteria were included in the study. Out of the total 315 patients studied, 92 (29.2\%) were females and 223 (70.8\%) were males with an average age of $52.6 \pm 16.3$ years. Clinical characteristics like symptoms on admission, severity and duration of illness, duration of the hospital stay, disease course, and outcomes are depicted in Table 1.

ECG abnormalities encountered in the study population with respect to the rate, rhythm, PR interval, axis deviation, QRS complex, QT interval, and ST and T-wave changes are shown in Figure 1.

Among the abnormal ECGs 255 (81\%), rhythm abnormalities were seen in 9 patients (2.9\%); rate abnormalities in 115 patients (36.5\%)-bradycardia (12.7\%) and tachycardia (23.8\%); and prolonged PR interval in $2.9 \%$ patients. Short QRS complex was seen in $8.3 \%$. QT interval was prolonged in $8.3 \%$ of the patients. There were significant changes in the ST and T segments (Table 2).

In logistic regression model (Table 3 ), subjects with moderateto-severe COVID-19 illness were twice likely to have at least one of the above-described abnormalities in ECG independent upon age, gender, and preexisting cardiac diseases [adjusted odds ratio 2.02
Table 1: Demographic and clinical characteristics of the study population

\begin{tabular}{|c|c|}
\hline Demographic and clinical variables & $N=315$ \\
\hline Age $($ mean $\pm S D)$ & $52.6 \pm 16.3$ \\
\hline \multicolumn{2}{|l|}{ Age distribution } \\
\hline $15-30$ years & $29(9.2 \%)$ \\
\hline $31-45$ years & 77 (24.4\%) \\
\hline $46-60$ years & $100(31.7 \%)$ \\
\hline $61-75$ years & $83(26.3 \%)$ \\
\hline$>75$ years & $26(8.2 \%)$ \\
\hline \multicolumn{2}{|l|}{ Gender } \\
\hline Male & $223(70.8 \%)$ \\
\hline Female & $92(29.2 \%)$ \\
\hline \multicolumn{2}{|l|}{ Duration of illness (at admission) } \\
\hline Median duration (days) & 3 \\
\hline Range (days) & $0-30$ \\
\hline \multicolumn{2}{|l|}{ Symptomatology } \\
\hline Asymptomatic & $69(21.9 \%)$ \\
\hline Symptomatic (at least one of the & $246(78.1 \%)$ \\
\hline below) & $154(62.6 \%)$ \\
\hline Fever & $133(54.0 \%)$ \\
\hline Cough & $74(30.0 \%)$ \\
\hline Breathlessness & $32(13.0 \%)$ \\
\hline Diarrhea & $21(8.5 \%)$ \\
\hline Anosmia/ageusia & $98(39.8 \%)$ \\
\hline Others & \\
\hline \multicolumn{2}{|l|}{ Comorbidities } \\
\hline Diabetes mellitus & $116(36.8 \%)$ \\
\hline Systemic hypertension & $96(30.5 \%)$ \\
\hline Heart diseases & $30(9.5 \%)$ \\
\hline Respiratory diseases & $15(4.6 \%)$ \\
\hline Thyroid diseases & $13(4.1 \%)$ \\
\hline Kidney diseases & $4(1.3 \%)$ \\
\hline At least one comorbid illness & $139(44.1 \%)$ \\
\hline No comorbidities & $176(55.9 \%)$ \\
\hline \multicolumn{2}{|l|}{ Disease course during hospital stay } \\
\hline Clinical deterioration & $68(21.6 \%)$ \\
\hline Clinically stable and improving & $231(73.3 \%)$ \\
\hline Subjects with oxygen requirement & $108(34.3 \%)$ \\
\hline $\begin{array}{l}\text { Subjects with ICU admission } \\
\text { ( }>48 \text { hours) }\end{array}$ & $63(20.0 \%)$ \\
\hline \multicolumn{2}{|l|}{ Duration of hospital stay } \\
\hline Median duration (days) & 9.00 \\
\hline Range (days) & $1-32$ \\
\hline \multicolumn{2}{|l|}{ Outcomes } \\
\hline Discharged & $296(93.9 \%)$ \\
\hline $\begin{array}{l}\text { Died (in-hospital mortality_all-cause } \\
\text { mortality) }\end{array}$ & $19(6.0 \%)$ \\
\hline
\end{tabular}

(95\% confidence interval 1.04-3.95)]. Among all subjects, ischemic changes in ECG (ST segment changes and T-wave inversion) appeared to be associated with systemic hypertension [adjusted odds ratio 1.73 (95\% confidence interval 0.96-3.11)] and respiratory failure [adjusted odds ratio 1.58 (95\% confidence interval 0.94-2.66)] after adjusting age, gender, and preexisting heart diseases. The above-mentioned associations showed a trend toward statistical significance. No other ECG changes had any significant association with clinical variables studied.

Of the 315 patients, 19 patients died ultimately due to COVID. The ECG abnormalities studied in these patients are shown in Figure 2. Prolongation of QTc interval (42\%) and tachycardia $(36.8 \%)$ were the commonest changes noted in them. The various ECG abnormalities encountered in the study population and the 


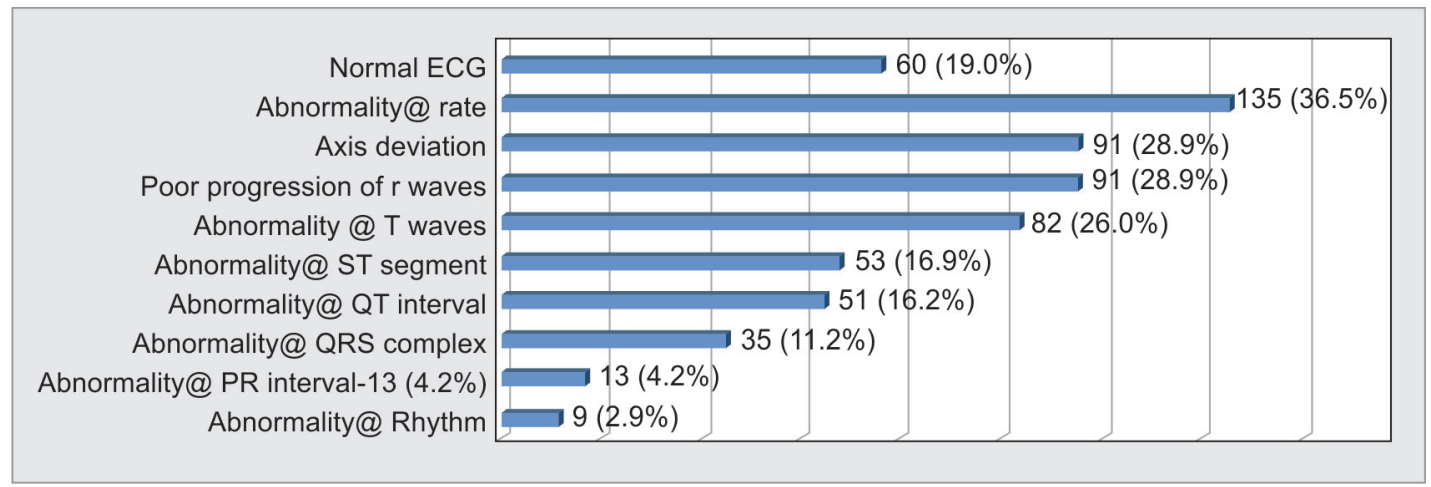

Fig. 1: ECG abnormalities in the study population

Table 2: Distribution of ECG changes at admission among the study population

\begin{tabular}{lc}
\hline ECG changes & Frequency $(\%)(\mathrm{N}=315)$ \\
\hline Normal ECG & $60(19.0 \%)$ \\
Irregular rhythm & $9(2.9 \%)$ \\
Abnormal rate & \\
Sinus bradycardia & $40(12.7 \%)$ \\
Sinus tachycardia & $95(23.8 \%)$ \\
Axis deviation & \\
Left & $91(28.9 \%)$ \\
Right & $0(0.0 \%)$ \\
PR interval & \\
Shortened PR interval & $4(1.4 \%)$ \\
Prolonged PR interval & $9(2.9 \%)$ \\
QRS complex & \\
Short QRS complex & $26(8.3 \%)$ \\
Widened QRS complex & $9(2.9 \%)$ \\
Poor progression of R-waves & $91(28.9 \%)$ \\
QT interval & \\
Shortened QT interval & $25(7.9 \%)$ \\
Prolonged QT interval & $26(8.3 \%)$ \\
ST segment & \\
ST elevation & $27(8.6 \%)$ \\
ST depression & $16(5.1 \%)$ \\
ST flattening/coving & $10(3.2 \%)$ \\
T-waves & \\
T-wave inversion & $75(23.8 \%)$ \\
Tall T-waves & $7(2.2 \%)$ \\
\hline &
\end{tabular}

Table 3: Logistic regression analysis of association between ECG changes and clinical variables

\begin{tabular}{lcc}
\hline $\begin{array}{l}\text { Variable-associated ECG } \\
\text { abnormalities }\end{array}$ & $\begin{array}{c}\text { Unadjusted odds } \\
\text { ratio (95\% confidence } \\
\text { interval) }\end{array}$ & $\begin{array}{c}\text { Adjusted odds ratio } \\
(95 \% \text { confidence } \\
\text { interval) }^{\epsilon}\end{array}$ \\
\hline $\begin{array}{l}\text { Ischemic changes in ECG } \\
\text { (ST segment elevation/ } \\
\text { depression and/or }\end{array}$ & & \\
$\begin{array}{l}\text { T inversion) } \\
\text { Systemic hypertension }\end{array}$ & $1.84(1.113-3.055)^{*}$ & $1.73(0.96-3.11)$ \\
$\begin{array}{l}\text { Respiratory failure on } \\
\text { admission }\end{array}$ & $1.71(1.049-2.79)^{*}$ & $1.58(0.94-2.66)$ \\
\hline${ }^{\epsilon}$ Adjustment model: age, gender, and preexisting heart diseases. ${ }^{*} p<0.05$
\end{tabular}

outcomes in each group are depicted in Figure 3. Adverse final outcomes were noted in $11.5 \%$ of the patients who had ST-T changes and QTc prolongation and $8.4 \%$ of the patients who had tachycardia.

\section{Discussion}

Myocardial injury associated with cardiac dysfunction and arrhythmias has been reported in infectious diseases. ECG changes observed in infections include hemorrhagic fever, ${ }^{8,9}$ leptospirosis, ${ }^{10}$ scrubtyphus, ${ }^{11}$ diphtheria, ${ }^{12}$ trichinellosis, ${ }^{13}$ and trypanosomiasis. ${ }^{14}$ Myocardial injury observed in dengue viral infection is evidenced by the presence of ECG abnormalities like atrial and ventricular premature beats, prolonged PR interval, bundle branch block $\mathrm{s}$, and ST and T segment changes. ${ }^{15}$ Abnormal ECG findings were found to be reported in $28 \%$ of the hospitalized patients infected with novel H1N1 influenza virus. ${ }^{16}$ Similarly, now there is growing evidence that SARS-CoV-2 also has the potential to have a negative impact on the cardiovascular system.

There are multiple proposed mechanisms for cardiac damage in COVID-19. These include cytokine release syndrome, ${ }^{17}$ direct myocardial damage as in viral myocarditis due to the interaction between virus and ACE $2,{ }^{18,19}$ coronary spasm, induction of a hypercoagulable state, plaque instability causing rupture, and acute coronary syndrome. ${ }^{20}$ Other potential mechanisms may include cardiac toxicity due to antivirals, steroids, and electrolyte abnormalities.

Even the earliest cases in China had evidence of myocardial injury $^{21}$ and previous studies did estimate the prevalence as between 1 and $7 \%$ of the patients and 26\% required intensive care. ${ }^{22}$ Studies by Shi et al. also inferred that cardiac involvement was associated with high mortality. ${ }^{23}$

In our study, we observed sinus tachycardia (23.8\%), sinus bradycardia (12.7\%), and atrial arrhythmia (3.5\%). This is in accordance with a study by Brit Long where the commonest ECG abnormality in COVID patients was sinus tachycardia followed by atrial fibrillation, ventricular arrhythmias, QTc prolongation, and ST-T segment changes. ${ }^{24}$ Atrial fibrillation (3.5\%), bradyarrhythmia (1.2\%), and nonsustained VT (10.4\%) were reported in another study conducted among 700 patients with severe acute respiratory syndrome due to SARS-CoV-2 infection. ${ }^{25}$

In our study, we encountered ischemic changes (ST segment elevation, T-wave inversion) in $32.4 \%$ of the COVID-19 patients irrespective of their underlying cardiac health. Italy published a research study of 28 COVID-19 patients who underwent angiogram 


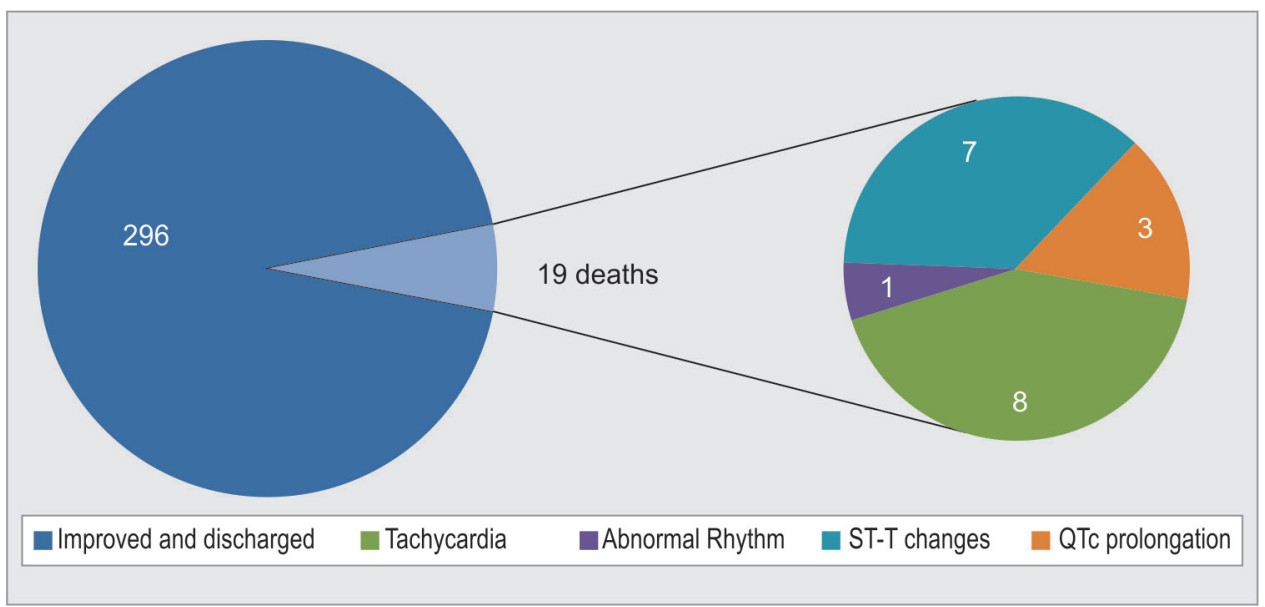

Fig. 2: Pie chart showing the final outcomes of the study population and various ECG abnormalities in the deceased population

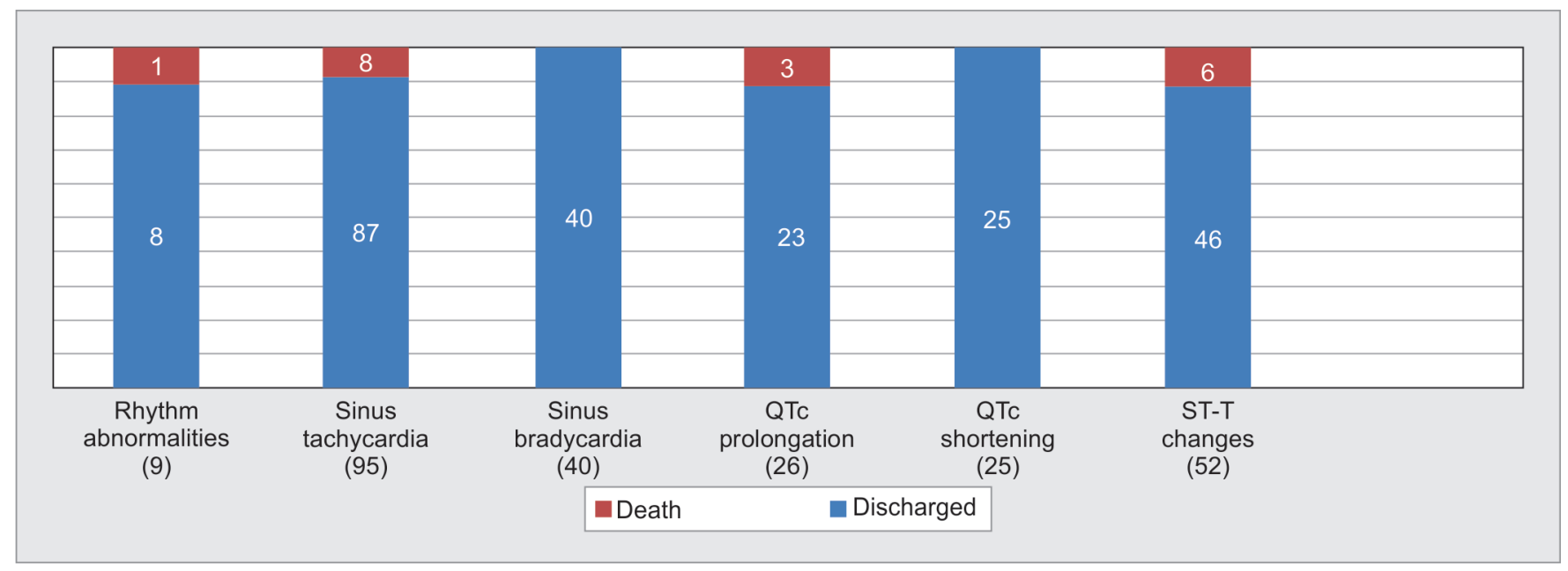

Fig. 3: Stacked column chart depicting the various ECG abnormalities and patient outcomes in each category

for ST elevation myocardial infarction in whom $86 \%$ had STEMI as the first presentation of COVID showing that acute coronary event had preceded systemic inflammation. Of these, $79 \%$ had typical chest pain, while $21 \%$ presented with dyspnea without any chest pain. $^{26}$

In the present study, $16.2 \%$ of the COVID-19 patients presented with QT segment changes (prolonged and shortened). QT interval prolongation has been noted in about 13\% of the COVID-19 patients. Major contributing factors to this particular abnormality may be the list of several (now unapproved) drugs previously used for COVID-19 treatment like hydroxychloroquine and azithromycin. ${ }^{27,28}$ QT interval prolongation may cause rhythm disturbances and hemodynamic instability requiring ICU admission and if not attended to may cause sudden cardiac death.

Pulmonary embolism may be a presenting issue of COVID-19 as well as its complication. A recent study of ECG findings in pulmonary embolism in COVID patients showed that abnormalities were mostly nonspecific including sinus tachycardia and minimal ST segment or T-wave changes. Specific and classic findings (classic S1Q3T3 pattern) were seen in less than $10 \%$ of the patients. ${ }^{29}$

All the 19 COVID patients who had succumbed to death had abnormal ECG findings. In a retrospective study to highlight the prognostic significance of ECG in COVID, Yang et al. have compared the ECG changes in survivors and nonsurvivors. ${ }^{30}$ It was observed that the nonsurvivors had significantly higher rates of prolonged QTc interval, axis deviation, arrhythmias, ST-T changes, and an overall higher abnormal ECG score. In our study population, QTc prolongation and tachycardia were the commonest changes in the deceased.

In a retrospective ECG analysis in the COVID-19 patients, Wang et al. have studied the ECG characteristics in the critically severe and severe group of patients. ${ }^{31}$ He has observed that $84.5 \%$ of the patients had abnormal ECG findings in the critically severe group as against $53 \%$ in the severe group. ST-T changes (48.5\%) and sinus tachycardia (30\%) were the most common abnormalities noted in the critically severe group of patients. In our study population, mortality was observed in $11.5 \%$ of the patients who had ST-T changes, $11.5 \%$ of the patients who had QTc prolongation, and $8.4 \%$ of those who had sinus tachycardia.

\section{Limitations}

Other factors that influence the ECG findings such as age, body mass index (BMI), electrolyte imbalances, inflammatory markers, 
and specifically cardiac markers were not considered in the analysis. We wish to extend the present study to find out the influence of SARS-CoV-2 virus on electrophysiology of cardiac muscle excluding these factors that affect the ECG parameters. Moreover, correlation of ECG findings with echocardiogram, clinical outcomes, and follow-up will help us understand the pathophysiology of cardiac diseases in COVID-19 disease. This will strengthen the race against COVID infection by enriching our knowledge and unraveling further mysteries around this mysterious infection.

\section{Conclusion}

In our study, COVID-19 patients presented with ischemic changes, rhythm abnormalities, and conduction defects. With SARS-CoV-2 having already gained momentum worldwide, it is important to deploy simple, cost-effective bedside examination, and diagnostic tests considering our limited health resources. ECG is of paramount importance in the Emergency COVID Department too as it is central to risk stratification and is predictive of an adverse outcome.

\section{HIGHLIGHTS}

- SARS-CoV-2 extends its prongs well beyond the lungs.

- There are multiple mechanisms for myocardial damage in COVID-19.

- Myocardial injury when present is a poor prognostic sign.

- ECG is a simple bedside diagnostic test to screen for cardiac abnormalities.

- The commonest ECG abnormalities in our study were sinus tachycardia, ischemic changes, and QTc segment abnormalities.

- It is crucial to monitor the patients for cardiac manifestations that will help to identify the complications and initiate prompt treatment.

\section{OrCID}

Deepalakshmi Kaliyaperumal @ https://orcid.org/0000-0002-35893860

Kumar Bhargavi 『 https://orcid.org/0000-0002-9799-0332

Karthikeyan Ramaraju (1) https://orcid.org/0000-0002-5577-5829

Krishna S Nair (1) https://orcid.org/0000-0002-5339-6470

Sudha Ramalingam ำ https://orcid.org/0000-0001-7800-9396

Murali Alagesan @ https://orcid.org/0000-0002-5876-4033

\section{References}

1. Huang C, Wang Y, Li X, Ren L, Zhao J, Hu Y, et al. Clinical features of patients infected with 2019 novel coronavirus in Wuhan, China. Lancet 2020;395(10223):497-506. DOI: 10.1016/S0140-6736(20)30183-5.

2. Inciardi RM, Lupi L, Zaccone G, Italia L, Raffo M, Tomasoni D, et al. Cardiac involvement in a patient with coronavirus disease 2019 (COVID-19). JAMA Cardiol 2020;5(7):819-824. DOI: 10.1001/ jamacardio.2020.1096.

3. Wang D, Hu B, Hu C, Zhu F, Liu X, Zhang J, et al. Clinical characteristics of 138 hospitalized patients with 2019 novel corona virus infected pneumonia in Wuhan, China. JAMA 2020;323(11):1061-1069. DOI: 10.1001/jama.2020.1585.

4. Zheng YY, Ma YT, Zhang JY, Xie X. COVID-19 and the cardiovascular system. Nat Rev Cardiol 2020;17(5):259-260. DOI: 10.1038/s41569020-0360-5.

5. Lin L, Xu YJ, He DP, Han Y, Tang GH, Yang ZM, et al. A retrospective study on clinical features of and treatment methods for 77 severe cases of SARS. Am J Chin Med 2003;31(6):821-839. DOI: 10.1142/ S0192415X03001521.
6. Lakkireddy DR, Chung MK, Gopinathannair R, Patton KK, Gluckman $\mathrm{TJ}$, Turagam M, et al. Guidance for cardiac electrophysiology during the COVID-19 pandemic from the Heart Rhythm Society COVID-19 Task Force; Electrophysiology Section of the American College of Cardiology; and the Electrocardiography and Arrhythmias Committee of the Council on Clinical Cardiology, American Heart Association. Circulation 2020;141(21):e823. DOI: 10.1161/ CIRCULATIONAHA.120.047063.

7. AjitMagadum A, Raj Kishore R. Cardiovascular manifestations of COVID-19 infection. Cells 2020;9(11):2508. DOI: 10.3390/cells 9112508.

8. Puljiz I, Kuzman I, Markotic A, Turcinov D, Matić M, Makek N. Electrocardiographic changes in patients with haemorrhagic fever with renal syndrome. Scand J Infect Dis 2005;37(8):594-598. DOI: 10.1080/00365540510036606.

9. Makela S, Kokkonen L, Ala-Houhala I, Groundstroem K, Harmoinen A, Huhtala $\mathrm{H}$, et al. More than half of the patients with acute Puumala hantavirus infection have abnormal cardiac findings. Scand J Infect Dis 2009;41(1):57-62. DOI: 10.1080/00365540802502629.

10. Sacramento E, Lopes AA, Costa E, Passos OL, Costa YA, Matos ED. Electrocardiographic alterations in patients hospitalized with leptospirosis in the Brazilian city of Salvador. Arq Bras Cardiol 2002;78(3):267-270. DOI: 10.1590/s0066-782×2002000300002.

11. Watt $G$, Kantipong $P$, Jirajarus $K$. Acute scrub typhus in northern Thailand: EKG changes. Southeast Asian J Trop Med Public Health 2002;33(2):312-313. PMID: 12236430.

12. Lumio JT, Groundstroem KW, Melnick OB, Huhtala H, Rakhmanova AG. Electrocardiographic abnormalities in patients with diphtheria: a prospective study. Am J Med 2004;116(2):78-83. DOI: 10.1016/ j.amjmed.2003.08.031.

13. Puljiz I, Beus A, Kuzman I, Seiwerth S. Electrocardiographic changes and myocarditis in trichinellosis: a retrospective study of 154 patients. Ann Trop Med Parasitol 2005;99(4):403-411. DOI: 10.1179/136485905X36307.

14. Goldbaum M, Ajimura FY, Litvoc J, de Carvalho SA, Eluf-Neto J. American trypanosomiasis and electrocardiographic alterations among industrial workers in São Paulo, Brazil. Rev Inst Med Trop Sao Paulo 2004;46(6):299-302. DOI: 10.1590/s0036-466520040 00600001.

15. Shivanthan, MC, Navinan MR, Constantine GR, Rajapakse S. Cardiac involvement in dengue infection. J Infec Dev Ctries 2015;9(4):338-346. PMID: 25881521.

16. Akritidis N, Mastora M, Baxevanos G, Dimos G, Pappas G. Electrocardiographic abnormalities in patients with novel H1N1 influenza virus infection. Am J Cardiol. 2010 Nov 15;106(10): 1517-1519. DOI: 10.1016/j.amjcard.2010.06.078. Epub 2010 Sep 24. PMID: 21059446.

17. Shi Y, Wang Y, Shao C, Huang J, Gan J, Huang X, et al. COVID-19 infection: the perspectives on immune responses. Cell Death Differ 2020;27(5):1451-1454. DOI: 10.1038/s41418-020-0530-3.

18. Clerkin KJ, Fried JA, Raikhelkar J, Sayer G, Griffin JM, Masoumi A, et al. COVID-19 and cardiovascular disease. Circulation 2020;141(20): 1648-1655. DOI: 10.1161/CIRCULATIONAHA.120.046941.

19. Xiong TY, Redwood S, Prendergast $B$, Chen M. Coronaviruses and the cardiovascular system: acute and long-term implications. Eur Heart J 2020;41(19):1798-1800. DOI: 10.1093/eurheartj/ehaa231.

20. Schoenhagen $P$, Tuzcu EM, Ellis SG. Plaque vulnerability, plaque rupture, and acute coronary syndromes: (multi)-focal manifestation of a systemic disease process. Circulation 2002;106(7):760-762. DOI: 10.1161/01.cir.0000025708.36290.05.

21. Bergamaschi L, D'Angelo EC, Paolisso P, Toniolo S, Fabrizio M, Angeli F, et al. The value of ECG changes in risk stratification of COVID-19 patients. Ann Noninvasive Electrocardiol 2021;26(3):e12815. DOI: 10.1111/anec.12815.

22. Wang D, Hu B, Hu C, Zhu F, Liu X, Zhang J, et al. Clinical characteristics of 138 hospitalized patients with 2019 novel coronavirus-infected pneumonia in Wuhan, China. JAMA 2020;323(11):1061. DOI: 10.1001/ jama.2020.1585. 
23. Shi S, Qin M, Shen B, Cai Y, Liu T, Yang F, et al. Association of cardiac injury with mortality in hospitalized patients with COVID-19 in Wuhan, China. JAMA Cardiol 2020;5(7):802-810. DOI: 10.1001/ jamacardio.2020.0950.

24. Long B, Brady WJ, Bridwell RE, Ramzy M, Montrief T, Singh M, et al. Electrocardiographic manifestations of COVID-19. Am J Emerg Med 2021;41:96-103. DOI: 10.1016/j.ajem.2020.12.060.

25. Bhatla A, Mayer MM, Adusumalli S, Hyman MC, Oh E, Tierney A, et al. COVID-19 and cardiac arrhythmias. Heart Rhythm 2020;17(9):14391444. DOI: 10.1016/j.hrthm.2020.06.016.

26. Stefanini GG, Montorfano M, Trabattoni D, Andreini D, Ferrante G, Ancona $\mathrm{M}$, et al. ST-elevation myocardial infarction in patients with COVID-19: clinical and angiographic outcomes. Circulation 2020;141(25):2113-2116. DOI: 10.1161/CIRCULATIONAHA.120. 047525.

27. Roden DM, Harrington RA, Poppas A, Russo AM. Considerations for drug interactions on QTC in exploratory COVID-19 (coronavirus disease 2019) treatment. Circulation 2020;141(24):e906-e907. DOI: 10.1161/CIRCULATIONAHA.120.047521.

28. Ramireddy A, Chugh H, Reinier K, Ebinger J, Park E, Thompson M, et al. Experience with hydroxychloroquine and azithromycin in the COVID-19 pandemic: implications for QT interval monitoring. J Am Heart Assoc 2020;9(12):e017144. DOI: 10.1161/JAHA.120.017144.

29. Kho J, loannou A, Van den Abbeele K, Mandal AKJ, Missouris CG. Pulmonary embolism in COVID-19: clinical characteristics and cardiac implications. Am J Emerg Med 2020;38(10):2142-2146. DOI: 10.1016/ j.ajem.2020.07.054.

30. Yang D, Li J, Gao P, Chen T, Cheng Z, Cheng K, et al. The prognostic significance of electrocardiography findings in patients with coronavirus disease 2019: a retrospective study. Clin Cardiol 2021;44(7):963-970. DOI: 10.1002/clc.23628.

31. Wang Y, Chen L, Wang J, HeX, Huang F, Chen J, et al. Electrocardiogram analysis of patients with different types of COVID-19. Ann Noninvasive Electrocardiol 2020;25(6):e12806. DOI: 10.1111/anec.12806. 